\title{
LAS EMPRESAS FLEXIBLES DE AUTOPARTES Y SU LOCALIZACIÓN EN EL ESTADO DE TLAXCALA
}

\author{
Flexible Auto Parts Companies and their \\ Location in the State of Tlaxcala
}

Celia Hernández Cortés ${ }^{1}$, Antonio Orozco Bolaños ${ }^{2}$

Fecha de recepción: 27 de febrero de 2016.

Fecha de aceptación: 30 de mayo de 2016.

1- Nacionalidad: Mexicana. Grado: Doctorado en Economía por el Colegio de Postgraduados, campus Puebla. Especialización: Economía, Análisis regional y territorial. Adscripción: Centro de Investigaciones Interdisciplinarias sobre Desarrollo Regional (CIISDER), Universidad Autónoma de Tlaxcala. Correo: chernandezcortes@ yahoo.com.mx

2- Nacionalidad: Mexicana. Grado: Maestro. Especialización: Economía, Análisis regional y territorial. Adscripción: Centro de Investigaciones Interdisciplinarias sobre Desarrollo Regional (CIISDER), Universidad Autónoma de Tlaxcala. Correo: s_anto10@hotmail.com 


\section{Resumen}

Este trabajo aborda los elementos de localización que las industrias de autopartes instaladas en la entidad federativa de Tlaxcala, toman en cuenta para su ubicación. Nuestro propósito es determinar estos elementos y caracterizarlos para observar la pervivencia de los factores weberianos clásicos y aquéllos que responden a la forma de producción flexible. Asimismo, nos interesa saber si las empresas de autopartes, se ubican en los parques industriales instalados en la entidad, a partir de la década de los setentas o se encuentran fuera de estos espacios industriales, desarrollados para dar condiciones al desarrollo del capital en su forma concentrada. El trabajo presenta tres apartados: el primer epígrafe presenta la discusión teórica sobre la localización económica durante el fordismo y posfordismo, el segundo expone en forma resumida las condiciones de industrialización en la entidad y una tercera parte incluye las características que observamos en las empresas flexibles de autopartes en la entidad.

Palabras clave: localización económica, empresas flexibles, autopartes, Tlaxcala.

\section{Abstract}

This work discusses the localization elements the auto parts industry installed in the federal state of Tlaxcala, taking into account its location. Our purpose is to identify and characterize these elements to observe the survival of classical Weberian factors and those corresponding to the shape of flexible production. We also want to know if auto parts companies are located in industrial parks installed in the state, from the late seventies or outside these industrial spaces developed to provide conditions for the development of capital in form concentrated. The paper presents three sections: the first section presents the theoretical discussion of the economic location during Fordism and post-Fordism, the second out in summary form the conditions of industrialization in the state and a third part includes the features seen in flexible companies auto parts in the state.

Keywords: Economic location, flexible firms, auto parts, Tlaxcala. 


\section{Introducción}

$\mathrm{L}$ a industria de autopartes o de fabricación de equipo de transporte, es la más representativa de la forma flexible de producción en el sector manufacturero local. La magnitud de su análisis radica en identificar y corroborar las características flexibles de estas empresas, de las más dinámicas en el contexto global.

La importancia de reconocer a las empresas flexibles de autopartes en la entidad de Tlaxcala $y$, hacerlas visibles, constituye el punto de partida para realizar este trabajo de investigación en donde se identifican los elementos que permitan explicar de manera más amplia la presencia de estas empresas en la geografía local. Para lograr lo anterior nos propusimos integrar elementos teóricos, documentales y empíricos a efecto de conocer las características de las empresas flexibles de autopartes, su importancia dentro de la estructura industrial y la forma en que se han venido instalando en el territorio estatal.

En lo teórico, se identificaron y seleccionaron argumentos, de diversos autores, que hicieron posible construir la estructura central de la investigación; la información empírica fue obtenida mediante la aplicación del instrumento (entrevista) a los directivos de las empresas de autopartes, la muestra alcanzada es significativa al representar el 50\% del total de las empresas del subsector. Los resultados obtenidos permiten rebasar la presunción inicial de que la localización de las empresas de equipo de transporte en el territorio estatal, está determinada principalmente por la cercanía de la empresa Volkswagen; y reconocer el conjunto de elementos de localización de las empresas de equipo de transporte de la entidad, sustentado en tres vértices fundamentales: la fuerza de trabajo, la logística carretera y la cercanía del mercado.

La estructura del trabajo se integra por tres partes: la primera expone el entorno teórico de la localización industrial, durante el fordismo y posfordismo; la segunda la contextualización de la industrialización tardía en el estado de Tlaxcala y la tercera, las características de las empresas flexibles de la industria de autopartes en Tlaxcala.

\section{Entorno teórico de la localización económica.}

La localización económica constituye la estrategia competitiva inicial de las empresas que adoptan alguna forma de producción capitalista. Las teorías clásicas sobre la localización económica son el basamento a partir del cual se han derivado otros enfoques para explicar la localización industrial.

Las teorías clásicas sobre la localización económica de autores como Von Thünen (1826), Weber (1909), Christaller (1933), Lösch (1940) e Isard (1956) parten de supuestos donde uno de ellos, es el de competencia perfecta. No obstante, estas aportaciones teóricas dieron origen a otras investigaciones como: los distritos industriales (Becattini, 1989), La localización industrial (Precedo y Villarino, 1992), El posfordismo y sus espacios (Lipietz, 1994), La teoría de la localización (Duch, 2005) entre otros, las cuales profundizaron en la explicación de la localización industrial. Y más recientemente, se registran aportaciones novedosas sobre la relocalización y 
deslocalización industrial de autores como Garrido (2006) y Sinisterra (2009). La complejidad económica en la etapa global actual impide que con una sola teoría se expliquen los patrones de localización industrial de cualquier país.

Las teorías clásicas se fueron estructurando a partir de enfoques diversos, específicamente para el análisis de la localización industrial, encontramos los trabajos de Alfred Weber y de Walter Isard. Von Thünen se concentró en el estudio de la localización en la agricultura; por su parte Christaller y Lösch aportaron elementos sobre la localización de las actividades terciarias.

Elegir un lugar específico para instalar una empresa, debe responder a determinadas preguntas: ¿Dónde deben ubicarse las empresas? ¿Por qué razones un lugar debe ser elegido? ¿Qué ventajas existen o se ofrecen? ¿En qué condiciones se pretende realizar la producción y reproducción del capital? ¿Cuáles son los principales factores de localización de las empresas en un lugar determinado?

\subsection{Las teorías de la localización industrial clásicas}

Después de la teoría de los círculos concéntricos de Von Thünen en 1826 la cual giró alrededor de la determinación de los precios de la tierra, la calidad de esta y los costos de transporte y donde la ciudad o el núcleo de población central representó el punto de referencia para la determinación de los costos de transporte y las rentas de las tierras. Alfred Weber, hermano del sociólogo Max Weber, estableció las bases teóricas para la localización industrial a partir de sus estudios de la localización de la industria alemana a principios del siglo XX. Weber, en lugar de seguir los planteamientos marxistas encaminósus propósitos retomando las aportaciones de la Teoría Económica Neo-Clásica ${ }^{3}$ cuya época de mayor auge se dio desde principios del siglo XX hasta los años 60s.

Weber tiene especial preocupación por encontrar la localización optima de una empresa abstracta, aislada del resto de la economía, sin recibir influencias de ella; de igual forma considera que el empresario buscará la mejor localización que le permita minimizar los costos totales, en particular los de transporte. Para ello asume varios supuestos: rendimientos constantes a escala; disponibilidad de insumos para la producción en forma ilimitada; de igual forma indicó que los insumos están localizados en pocas fuentes. Por el lado de la demanda, esta se mantiene fija y en cada lugar, y los costos de transporte, para cada bien, son directamente proporcionales a su peso y a la distancia que transportan. También consideró las ventajas que da la aglomeración de empresas. Al igual que Von Thünen, Weber destaca la influencia de la distancia como determinante del coste de transporte en el proceso productivo, y por consiguiente en la localización (Salguero, 2006:8). Sin embargo, esta se puede modificar a partir de los requerimientos de mano de obra, en particular el costo de ésta, y la cercanía entre las fabricas (aglomeración). Cuando el ahorro en el coste de la mano de obra [y el de la tendencia a la aglomeración] sea mayor al coste de transporte, entonces las empresas buscarían ubicarse en estos sitios (Duch, 2005:13).

Estos factores weberianos de la localización industrial, son los antecedentes más preciados sobre los que se desenvolvió una de las formas productivas más representativas del capitalismo, como lo fue el

3- Por Teoría Económica Neo-Clásica entendemos al cuerpo de análisis económico desarrollado a partir de 1870 por Jevons, Walras oEdgeworth y sus seguidores los cuales conforman el grueso de la Teoría Económica ortodoxa basada en el modelo de competencia perfecta. 
fordismo ${ }^{4}$. Así la industrialización de los países considerados más avanzados y los llamados de menor desarrollo alojaron a empresas industriales durante el siglo XX pero sólo en aquéllos lugares que garantizaran bajos costos de mano de obra, materias primas y menores costos de transporte, factores que junto a elementos naturales, técnicos, sociales y culturales garantizaron el incremento de ganancia.

Con la teoría del lugar central de Walter Christaller recogida en su obra "Los lugares centrales en Alemania meridional" (1933), el geógrafo cuantitativo alemán, implica a la ciudad como el espacio privilegiado donde se aglutinan las actividades (terciarias) lo que contribuye a la instalación también de la industria. Lo anterior le permitió a August Lösch (1906-1945) elaborar su Teoría Económica Espacial en 1938 y argumentó a favor de la localización industrial a partir del conjunto de condiciones del lugar más que por los costos mínimo, presentó un modelo completo de equilibrio general. En este modelo describe las interrelaciones de las diversas localizaciones.

En Estados Unidos, el economista Walter Isard (1970) estableció un modelo teórico, en busca de la localización optima, cuyo objetivo era determinar la región o regiones donde la industria podría alcanzar el nivel más reducido de sus costes de producción, así como la distribución de sus productos en el mercado, atribuyendo efectos significativos a los costes del transporte en la localización industrial (Bustos, 1993:60). En el modelo se interpreta que las localizaciones cercanas al mercado pueden perder su ventaja, cuando en otra región más alejada se introducen mejoras en el transporte, haciéndolo más eficiente. La influencia de Weber sobre Isard refleja la importancia de los costos en su teoría de localización industrial, al ponderar con mayor énfasis, los costos de producción y del transporte (Isard, 1970:236).

La revisión de los principales argumentos de las teorías clásicas de la localización, permiten visualizar la relevancia otorgada a los costos, específicamente al del transporte, como el factor fundamental para la localización de las empresas en una región determinada, no obstante Weber e Isard también incluyen a la mano de obra como otro factor atrayente. Los supuestos de estos modelos son altamente débiles al manejarse en términos de competencia perfecta, prácticamente imposibles en la realidad.

Los aportes de estas teorías son fiel reflejo de sus circunstancias en el tiempo y en el espacio, pues con excepción de Von Thunen, las demás (Weber, Christaller, Lösch e Isard) desarrollaron sus planteamientos a partir de la realidad económica que observaban, desde principios hasta mediados del siglo XX, fase del capitalismo industrial que se desarrolló en gran parte de los países occidentales, donde el factor central de la localización de industrias estuvo marcado por los costos de transporte, al que podríamos llamarle "el gran costo", a través del cual se fijaban las posibilidades de rentabilidad. Estas teorías fueron claves para la evolución de las actividades económicas, específicamente las industriales, pues nutrieron con modelos y argumentos las conveniencias de su localización en determinados espacios geográficos.

\subsection{Las teorías de localización industrial en el posfordismo}

De acuerdo con Kuri (2003) las principales características del modelo fordista muestran una forma de organización industrial de carácter vertical, donde las decisiones y soluciones en la producción e innovación se determinan desde la punta de la empresa; con un esquema de producción en serie, estandarizada

4- El sistema fordista de producción se conoce a la forma en que Henry Ford, durante la primera década del siglo XX, produce automóviles en línea a través de grandes industrias, cuyo dominio se extendió hasta finales de la década de los años setenta. 
y homogénea para atender un mercado de masas, mediante el uso de maquinaria especializada diseñada para cumplir compromisos de producción de largo plazo; operada por personal no necesariamente calificado en una misma línea de montaje, concentrando todo el proceso en una planta con el propósito de lograr economías de escala. Después de la Segunda Guerra Mundial los países industriales crecieron rápidamente, pero desde finales de los años sesenta, el mundo industrial entró en un periodo de dificultades, las perturbaciones económicas se convirtieron en una crisis general del sistema industrial (Piore y Sabel, 1990).

La década de los setenta del siglo XX marcaron la eclosión de la crisis fordista, cuando las dificultades económicas y sociales causaron estragos e incertidumbre en la producción en serie por sus características de inversión y compromisos de largo plazo, y por los costos de funcionamiento de sus equipos. La producción masiva fue cediendo entonces, su lugar a otro tipo de producción denominado posfordista que incorporó tecnología más flexible, que se adaptaba a la diversidad y a las nuevas necesidades del mercado ${ }^{5}$

Esta restructuración productiva del capitalismo obedeció fundamentalmente a su necesidad de adaptarse ante el desencadenamiento de sus propias contradicciones. Los cambios de las necesidades del capital generaron inflación y caída en las condiciones generales de los asalariados al disminuir el salario real por efecto del incremento de los precios y sus prestaciones salariales como requerimiento para incrementar la tasa de ganancia. Esto significó para la economía norteamericana y en Europa, el deterioro de la competitividad, obligando a abandonar el tipo de cambio fijo, y a adoptar tipos de cambio fluctuantes, medida que afectó a la producción en serie por sus compromisos de producción a largo plazo.

La inflación y la incertidumbre restringieron la actividad industrial, agravándose la situación económica en el mundo al conjugarse, con elevados tipos de cambio; lo anterior afectó de manera severa al modelo de la producción en serie que fue cediendo su espacio a la producción flexible (Piore y Sabel, 1990: 82-89). Piore y Sabel enlazan su enfoque teórico alrededor de una cadena de sucesos históricos de carácter macroeconómico en los Estados Unidos y Europa, que vulneraron la estabilidad sobre la que descansaban las empresas industriales en el sistema fordista, forzando la restructuración productiva y el camino a la transición.

Esta metamorfosis no puede dejar de explicarse en el marco de una óptica más crítica, que desnuda las contradicciones del sistema capitalista. Así, de inicio David Harvey, geógrafo anglosajón marxista, establece que "asistimos a una transición histórica que aún no ha terminado y que, en todo caso, como el fordismo, está destinada a ser parcial en ciertos aspectos importantes" (Harvey, 1998:197). Harvey es uno de los principales teóricos críticos que ha analizado la crisis del sistema fordista de producción y su transición al sistema flexible; desarrolló su tesis mediante la revisión de las contradicciones del capitalismo y su tendencia a la crisis, en donde se registran ciclos de lo que denomina hiper-acumulación. Desde luego, su afirmación de una transición inacabada y de un sistema no extinto, son parte de esa realidad contradictoria que busca explicar.

5- Los años setenta y ochenta fueron testigos de cambios radicales en la economía mundial que afectaron aspectos clave como la organización industrial, la producción de tecnología, la dinámica de los mercados y el manejo de las políticas económicas tanto a nivel internacional, como nacional y regional. Una forma de explicar tales transformaciones, es a partir del cambio en el patrón de organización industrial llamado fordista que prevaleció en los años de la posguerra, por otro conocido como posfordista ya entrada la década del setenta (Kuri, 2003:59). 
Para él, la crisis del fordismo está estrechamente relacionada con tres rasgos fundamentales del capitalismo: a) el capitalismo tiende al crecimiento, b) el crecimiento de los valores reales depende de la explotación de la fuerza de trabajo en la producción, y c) el capitalismo es necesariamente dinámico en los niveles tecnológico y organizativo (Harvey,1998:200). En la lógica del capital "un ritmo constante de crecimiento es esencial para la salud del sistema económico, ya que las ganancias así como la acumulación del capital sólo pueden garantizarse a través del crecimiento" (Harvey, 1998:203).

En cuanto al crecimiento de los valores reales, este "siempre se funda en una brecha entre aquello que la fuerza de trabajo obtiene y aquello que ella crea" (Harvey, 1998:203). Esa diferencia además de mostrar la explotación de la fuerza de trabajo, exige -también en la lógica del capital- la necesidad de su control, ya que sobre esa relación de explotación se sostiene la reproducción y acumulación del modo de producción capitalista. La dinámica tecnológica y organizativa del capital son los instrumentos elite de la competencia capitalista, en donde la innovación, la investigación y el desarrollo tecnológico son la punta de lanza en la búsqueda de la perennidad de éste modo de producción. En la economía capitalista se establecen metas macroeconómicas siempre tendientes al incesante crecimiento, pero el producto derivado del mismo no es repartido con equidad. "Según Marx, el capitalismo como sistema político-económico está organizado para el lucro, no para el bienestar colectivo" (Martinelli, 2010:24).

La evolución histórica del capitalismo si bien nos muestra que no ha salido ileso de sus contradicciones internas, mantiene su vigencia en virtud de haber, en su trayecto, diversas formas medidas y respuestas ante sus crisis de hiper-acumulación, sobre todo, después de 1929 pues la producción destinada a la ganancia sigue siendo el principio básico organizador de la vida económica (Harvey, 1998). Entre las medidas y respuestas del capital a sus recurrentes crisis de hiper- acumulación, Harvey (1998:204-205) destaca las siguientes:

$1^{\circ}$ La devaluación de las mercancías, de la capacidad productiva, del dinero, acompañada quizá por una franca destrucción, es una de las formas de enfrentar los excedentes de capital. $2^{\circ}$ El control macroeconómico, a través de la Institucionalización de algún sistema de regulación, puede contener, quizá por un período considerable, el problema de la hiper- acumulación.

$3^{\circ}$ La absorción de la hiper-acumulación a través de un desplazamiento temporal y espacial proporciona, un terreno mucho más rico y duradero, pero también más problemático, a partir del cual se puede tratar de controlar el problema de la hiperacumulación.

La tercera medida enunciada por Harvey, compete básicamente a las decisiones estratégicas de las empresas. Mediante desplazamientos temporales, los elevados excedentes financieros son orientados a proyectos de largo plazo para amortiguar y minimizar los efectos de la crisis; o bien, a través de desplazamientos espaciales expanden sus actividades hacia otros territorios que les permita continuar con su proceso de acumulación.

Cuando los desplazamientos en el tiempo y en el espacio dejaron de ser eficientes dentro del fordismo, se requirió otro sistema productivo capaz de resolver el problema de la hiper- acumulación. Así a mediados de la década de los setenta del siglo XX, se hace visible el sistema flexible, cuyos embriones ya se 
habían gestado durante la fase de crisis fordista, haciendo uso de otro tipo de desplazamientos. Harvey analiza esta mutación y señala dos estrategias de las que se vale el sistema flexible para enfrentar el problema de la hiper-acumulación.

La acumulación flexible parece constituir una simple recombinación de las dos estrategias básicas definidas por Marx para obtener ganancias (plusvalía). La primera, llamada plusvalía absoluta, la cual se sustenta en la extensión de la jornada de trabajo con relación al salario necesario para garantizar la reproducción de la clase obrera en un determinado nivel de vida. El desplazamiento hacia la prolongación de las horas de trabajo, junto con una reducción global de los estándares de vida, sea por erosión de los salarios reales sea por el desplazamiento del capital de las corporaciones, de regiones de altos salarios a regiones de bajos salarios, capta una de las facetas de la acumulación flexible de capital. (Harvey, 1998:210).

La principal faceta del capital bajo esta forma de acumulación a la que se refiere Harvey, denota una ruda explotación de la fuerza de trabajo, la cual es abaratada y precarizada dramáticamente, despojando además de sus derechos y beneficios laborales a los trabajadores, los cuales se ganaron en el modelo anterior.

La segunda estrategia está asociada a la denominada plusvalía relativa, la cual se realiza a partir de la transformación organizativa y tecnológica con el propósito de generar ganancias temporarias para las firmas innovadoras y beneficios más generalizados en la medida en que se reducen los costos de los bienes que definen el nivel de vida de la fuerza de trabajo. También en este caso, la proliferante violencia de las inversiones, que reducen el empleo y los costos de la mano de obra en toda la industria, desde la extracción de carbón hasta la producción de acero y hasta los servicios bancarios y financieros, ha sido un aspecto muy visible de la acumulación de capital en la década de 1980. (Harvey, 1998:210).

Para comprender la nueva morfología del trabajo bajo la forma de acumulación flexible, en donde el capital es el factor predominante, Bialakowsky y Antunes (2009) nos brindan su tesis. “....Si el trabajo aún es central para la creación de valor, el capital, por su parte, lo hace oscilar, ora reiterando su sentido de perennidad, ora imprimiendo su enorme superfluidez, de la cual son ejemplos los precarizados, flexibilizados, temporarios, más allá del enorme ejército de desempleados..." (Bialakowsky y Antunes, 2009:33) Las dos plusvalías absoluta y relativa dentro del sistema de acumulación flexible, constituyen los mecanismos según Harvey, para darle viabilidad acumulativa al capital. Pero este autor incorpora al análisis otro elemento de alta significancia.

El tiempo de rotación del capital -que es siempre una de las claves de la rentabilidad capitalista- se redujo de manera rotunda con el despliegue de las nuevas tecnologías productivas (automatización, robots, etc.) y las nuevas formas organizativas (como el Sistema de entregas «justo-a-tiempo» en los flujos de inventarios, que reduce radicalmente los que hacen falta para mantener la producción en marcha). Pero la aceleración del tiempo de rotación en la producción habría sido inútil si no se reducía también el tiempo de rotación en el consumo.

Gutiérrez (2006:72) refiere las implicaciones en el consumo, donde se encuentra la llamada "obsolescencia planificada", expresada en que "el ciclo de vida del producto es cada vez más corto, lo que le permite presionar sobre la demanda efectiva". Las afirmaciones de los tres autores resumen que el corto ciclo de duración de las mercancías eleva la rotación del capital, una forma excesivamente pragmática y poco ortodoxa de enfrentar la crisis. Ahora las mercancías duran menos y por lo tanto los consumidores tienen que destinar más ingresos para mantener el mismo nivel de consumo, favoreciendo la creciente 
rotación del capital y la rápida obtención de la ganancia. El capital impone así su poder sin necesidad de enfrentar normatividad reguladora alguna, sobre una posible certificación de durabilidad mínima de las mercancías.

Por otro lado, el exceso de inventarios -que reflejan la saturación de mercancías- fue síntoma inequívoco de la falta de diversidad en el mercado. El sistema fordista al final de los sesentas del siglo XX no fue capaz de ofrecer al mercado diversidad en la gama de productos, su organización rígida y limitada se vio desbordada ante las nuevas necesidades y exigencias de productos que requerían variaciones constantes para mantener la demanda basada precisamente en lo novedoso, en lo diverso.

El advenimiento del sistema flexible, se sustentó en la incorporación de tecnología en la informática y la electrónica, se logró por un lado, acrecentar la velocidad de respuesta a la diversidad de la demanda, y por otro, reducir el tiempo de reproducción de la fuerza de trabajo al disminuir la absorción de ésta en la composición orgánica del capital y desplazar mano de obra; además de extender la jornada de trabajo - plusvalía absoluta- al aprovechar la existencia de un creciente ejercito industrial de reserva, producto de la crisis del fordismo. La crisis del sistema fordista no significó su destrucción total y definitiva. Sus problemas de sobreacumulación crearon la necesidad de acelerar su transición hacia otra forma de acumulación, hasta hoy no acabada como lo es el posfordismo.

$\mathrm{Al}$ respecto, Contreras (2000) señala que Wilson (1992) intentó determinar hasta qué punto se había implantado, en las maquiladoras, los modelos de producción flexible, para ello clasificó a las maquiladoras en tres tipos de planta: posfordista, fordista y ensambladoras de trabajo intensivo. Los resultados señalan que el $21 \%$ de las plantas utilizaba una alta proporción de tecnología de producción asistida por computadora, así como un alto grado de prácticas organizacionales flexibles y relaciones de integración internacional de producción de las actividades productivas basadas en el método "justo a tiempo", lo cual las calificaba como fábricas flexibles posfordistas. Otro 35\% de las plantas es clasificado como manufactura fordista. Se trata de maquiladoras que producen bienes manufacturados, pero que no utilizan tecnología flexible; y las plantas ensambladoras de trabajo intensivo constituyen la mayor parte con el 44\% de su muestra. (Contreras, 2000:99,100). Otro investigador interesado en dilucidar la ausencia de fronteras en estas formas de producción del capitalismo industrial, ha sido Gustavo De la Garza (2012).

Desde el punto de vista de las configuraciones productivas, la mayoría de las maquilas son ensambladoras que utilizan tecnología intermedia (maquinizada no automatizada); prácticamente no realizan investigación y desarrollo, ya que la tecnología la obtienen de sus matrices; han introducido cambios organizacionales, aunque la mayoría en las formas más simples como los círculos de calidad; es probable que lo que predomine sea el taylorismo y el fordismo mezclado con aspectos parciales, comúnmente los más sencillos del toyotismo (De la Garza,2012:259).

De la Garza recurre a uno de sus trabajos, acerca de los modelos de producción en la maquila de exportación en México, para mostrar una serie de combinaciones entre organización fordista y el toyotismo precario en el análisis de algunas empresas mexicanas.

Estos datos disímbolos permiten observar todavía, la magnitud del sistema fordista en el proceso productivo de un gran número de empresas, sobre todo en países depositarios de una parte de los procesos industriales centrales, mientras el sistema posfordista o flexible se asume como dominante en los países centrales dentro del capitalismo industrial. Sin embargo, la transición del fordismo al posfordismo realmente no es un asunto terminado. Más bien, pareciera que la restructuración industrial 
necesita de la coexistencia y complemento de ambas formas de producción dictada por las necesidades de acumulación.

En el sistema flexible las variadas tareas suponen desde luego, mayor responsabilidad de la fuerza de trabajo, la cual debe estar dotada de una mejor formación técnica y profesional, y ser colocada dentro del proceso productivo con altos niveles de educación y calificación para seguir siendo capacitada, sobre todo en el manejo de tecnologías de la información y comunicación, indispensables en la empresa posfordista. De esta manera, el saber y el conocimiento de la fuerza de trabajo terminan por expresarse como la base del valor y de la capacidad innovadora, al vigilar la calidad de la producción, y ejercer supervisión en los procesos y la mejora continua, pues ahora son trabajadores polivalentes, multifuncionales y capacitados, requisitos apegados a las reglas de aceptación laboral de la restructuración global del capital.

En cuanto a su retribución económica, arrinconados por la nueva composición orgánica del capital, es decir, por la caída del salario dentro de los costos de producción y por la restructuración de las leyes laborales que dictan otras formas de contratación, se rompe la seguridad laboral y social de los trabajadores, y se imponen percepciones precarias, situación que deteriora sus condiciones de vida, destruyendo de esta manera la estructura laboral. En este sentido, el posfordismo está caracterizado por una dinámica más despiadada y violenta en las condiciones de trabajo, situación que define la forma en que el sistema responde a la cambiante y diversa demanda del mercado.

\section{La industrialización tardía en Tlaxcala}

Tlaxcala inicia tardíamente su proceso de industrialización a partir de las políticas de descentralización impulsadas en el régimen de Luis Echeverría (1970-1976), que entre otros objetivos se propuso la descentralización de actividades de la Ciudad de México (descentralización industrial), con la finalidad de reducir las desigualdades regionales, y estimular el desarrollo de las zonas marginadas(Garza, 1989)6. El autor destaca, "el programa de parques y ciudades Industriales considerados los instrumentos concretos para la descentralización industrial", y periodiza el desarrollo de éstos en dos grandes etapas: i) la etapa experimental, 1953-1970, y ii) la etapa de expansión, 1971- 1987. En esta etapa se implementaron mecanismos de descentralización que buscaban el ordenamiento del territorio y crear condiciones para la reproducción del capital en regiones sin tradición industrial, Tlaxcala fue incorporada para su industrialización, en la etapa de expansión del Programa de Parques y Ciudades Industriales, mediante la construcción de Ciudad Industrial Xicoténcatl, cuyas ventas iniciaron en 1978 y fue acreditada como propiedad estatal al obtener su acta constitutiva en 1980(Garza, 1990:658).

Alentado por dicho programa, instrumentado por el Gobierno Federal en 1971, el estado de Tlaxcala registró un importante cambio estructural a partir de la segunda mitad de los años setenta del siglo anterior, a través de un intenso proceso de industrialización, el cual se sustentó en la creación de diversas zonas industriales en la geografía estatal.

En la transición de lo rural a lo urbano las actividades secundarias y terciarias desplazaron a la agricultura como el sector jerárquico de la estructura económica. En el 2011 la composición del PIB estatal,

6- La industrialización en México se inició en la década de los cuarenta a través de la implementación del modelo de sustitución de importaciones (ISI), sin embargo, espacialmente abarcó pocas ciudades: Ciudad de México, Toluca, Monterrey, Guadalajara y Puebla. 
a precios de 2008 destaca la actividad manufacturera con una participación del 38.0\% y las actividades terciarias (comercio y servicios) con un aporte del 59.1\%, en tanto, el sector primario solo contribuye con el 2.8\% (INEGI, 2013), esto refleja la pérdida de su importancia y de sus condiciones económicas.

Otros fenómenos relacionados es la concentración poblacional y otro la integración metropolitana. Actualmente, el territorio estatal está integrado a dos Zonas Metropolitanas: Puebla-Tlaxcala y TlaxcalaApizaco, donde viven 837, 880 tlaxcaltecas, equivalentes al 71.61\% de la población estatal y en el ámbito de ambas zonas se ubica la mayoría de parques y corredores industriales (Programa de Ordenamiento Territorial y Desarrollo Urbano para el Estado de Tlaxcala, 2013). En la primera Zona Metropolitana, están incluidos 20 municipios de la entidad y en la segunda suman 19; de esta manera, el fenómeno metropolitano tiene un alto impacto en el ordenamiento territorial al absorber dos terceras partes del total de los municipios. El incremento de las tendencias concentradoras de las actividades económicas y de la población en el estado, no son ajenas a la propia dinámica y exigencias del capital para favorecer la acumulación. Ahí donde se aglomera la población y la actividad económica, se genera infraestructura y equipamiento necesario para la reproducción del capital y de la fuerza de trabajo. Es el lugar donde confluyen las condiciones que facilitan el ciclo del capital.

\subsection{Política regulatoria nacional}

En México la industria automotriz se ha desarrollado a la luz de un conjunto de decretos automotrices que ha impulsado el gobierno federal desde 1962 a la fecha. Estos decretos han incluido consideraciones de funcionamiento tanto de la industria terminal (armadoras) como la de autopartes. De igual forma las estrategias que han utilizado las empresas automotrices para bajar costos de producción y monopolizar mercados, definen el desarrollo de la industria y su instalación inicial en el país a partir de 1925 con las líneas de ensamble de Ford; General Motors en 1935 y Chrrysler en 1938(Vicencio, 2007: 214).

Con el impulso del modelo de sustitución de importaciones a partir de la década de los cuarenta se establecen las bases para el desarrollo del capitalismo industrial del país. Establecida la infraestructura necesaria para el desarrollo industrial, en algunas ciudades del país, se emite el primer decreto en 1962 orientado a fomentar el desarrollo de la industria automotriz. En este no se fijaron límites para el número de industrias armadoras. En esa década se establecen Volkswagen (primero en el Estado de México -1964- y después en la ciudad Puebla en 1967), Ford se expande igual que General Motors y Chrysler y Nissan se instala en Cuernavaca. Las orientaciones de este primer decreto giraban alrededor de fortalecer el mercado interno, estableciendo límites a la importación de vehículos, de igual forma, se limitaba las inversiones del capital extranjero en las plantas fabricantes de autopartes (40\%) y se estableció un control de precios con el fin de contener las utilidades e incentivar la productividad, entre otras medidas. La producción se orientaba básicamente a proveer de unidades y autopartes al mercado interno.

Para 1972 se emite otro decreto que buscaba fomentar las exportaciones no únicamente la producción interna, sin embargo, el mercado de los Estados Unidos que era el “otro mercado" al que se le podía vender, se encontraba en recesión. Para 1977 se emite nuevamente otro decreto que busca incidir en lo mismo, es decir en las exportaciones. Las firmas que responden a esto, son las de autopartes, exportando el $50 \%$ de su producción total, no así las armadoras de producto final (Vicencio, 2007:218). 
A finales de la década de los setenta, cuando la industria de automóviles japonesa, inicia la penetración en el mercado mundial, con vehículos más pequeños, eficientes y más económicos, la respuesta de las armadoras norteamericanas y de otros países en México es la reestructuración productiva, en donde la trasferencia de tecnología, tiene un papel relevante. De igual forma las promociones de los trabajadores, se hacen a partir del desempeño individual y las aptitudes de los trabajadores no a partir de la antigüedad.

En la década de los ochenta, se vuelve a emitir otro decreto en 1983 buscando nuevamente la exportación de vehículos. Sin embargo, en estos diez años, las condiciones macroeconómicas, del país, fueron desfavorables por el déficit fiscal y el endeudamiento. En este periodo se da, la salida del gobierno, de la actividad económica industrial, con la venta de las acciones del gobierno a empresas extranjeras. En el sector automotriz fue la industria terminal. A finales del periodo, en 1989, se emite un nuevo decreto donde se autoriza por primera vez, la importación de vehículos nuevos al país, siempre y cuando la industria en su conjunto mantuviera un saldo favorable en su balanza comercial, de igual forma los vehículos ensamblados bajan su componente nacional a únicamente el 36\% (Vicencio, 2007:219-220).

En los noventa, con la entrada en vigor del Tratado de Libre Comercio (TLC), disminuyen las tarifas arancelarias tanto para la industria terminal como la de autopartes. Los fabricantes de autopartes tuvieron que elevar la calidad y reducir sus costos de producción para cumplir los requerimientos de los mercados de exportación. En 2003, se vuelve a publicar otro decreto con miras a aumentar la competitividad y fortalecer el mercado interno (Vicencio, 2007:224).

Junto a la política de regulación, que ha definido el nivel central de gobierno, se encuentran las estrategias que las empresas han desarrollado para su permanencia en el mercado. Al moverse de la producción fordista a la producción flexible, la industria automotriz, descentralizó funciones y procesos que antes estaban en la columna vertebral de las operaciones, se promovió la subcontratación, buscó la mejora continua y se estableció un conjunto de redes entre empresas para el desarrollo tecnológico, capacitación y planeación de inversiones.

En la industria terminar, como parte de estas estrategias se incorporan proveedores de primer nivel, provenientes desde sus países de origen, cuya calidad es reconocida en el nivel internacional lo que da paso al comercio intrafirmas, mientras que en las empresas de autopartes se sigue trabajando con un considerable número de operaciones manuales en paralelo con procesos semiautomáticos (Vicencio, 2007: 245). Lo anterior, habla de desarrollos distintos dentro de la misma industria.

\subsection{Los instrumentos jurídicos en Tlaxcala}

Desde la década de los setenta del siglo XX cuando el estado de Tlaxcala se inserta al Programa para la Promoción de Conjuntos, Parques y Ciudades Industriales hasta la fecha, la promoción de inversiones del estado se concibió a partir de las leyes de fomento industrial y económico. Más de cuatro décadas de evolución manufacturera fueron guiados por los ordenamientos jurídicos siguientes:

La Nueva Ley para el Fomento Industrial en el Estado de Tlaxcala (31/10/1973).

Ley de Fomento Económico del Estado de Tlaxcala (07/07/1998).

Ley de Fomento Económico del Estado de Tlaxcala (29/01/2002).

Ley de Fomento Económico del Estado de Tlaxcala (04/12/2009). 
Como consecuencia de la primera ley de fomento, entre otras cosas, se establecen "los Corredores Industriales de Apizaco- Huamantla y el de Texmelucan-Tlaxcala, considerando como factores de localización de éstos, las carreteras que unen a estas Ciudades entre sí y a partir de los límites del Estado, en la parte sur hasta la Ciudad Capital"(Véase mapa 1).

Mapa 1. Tlaxcala: localización de los corredores industriales, 1973.

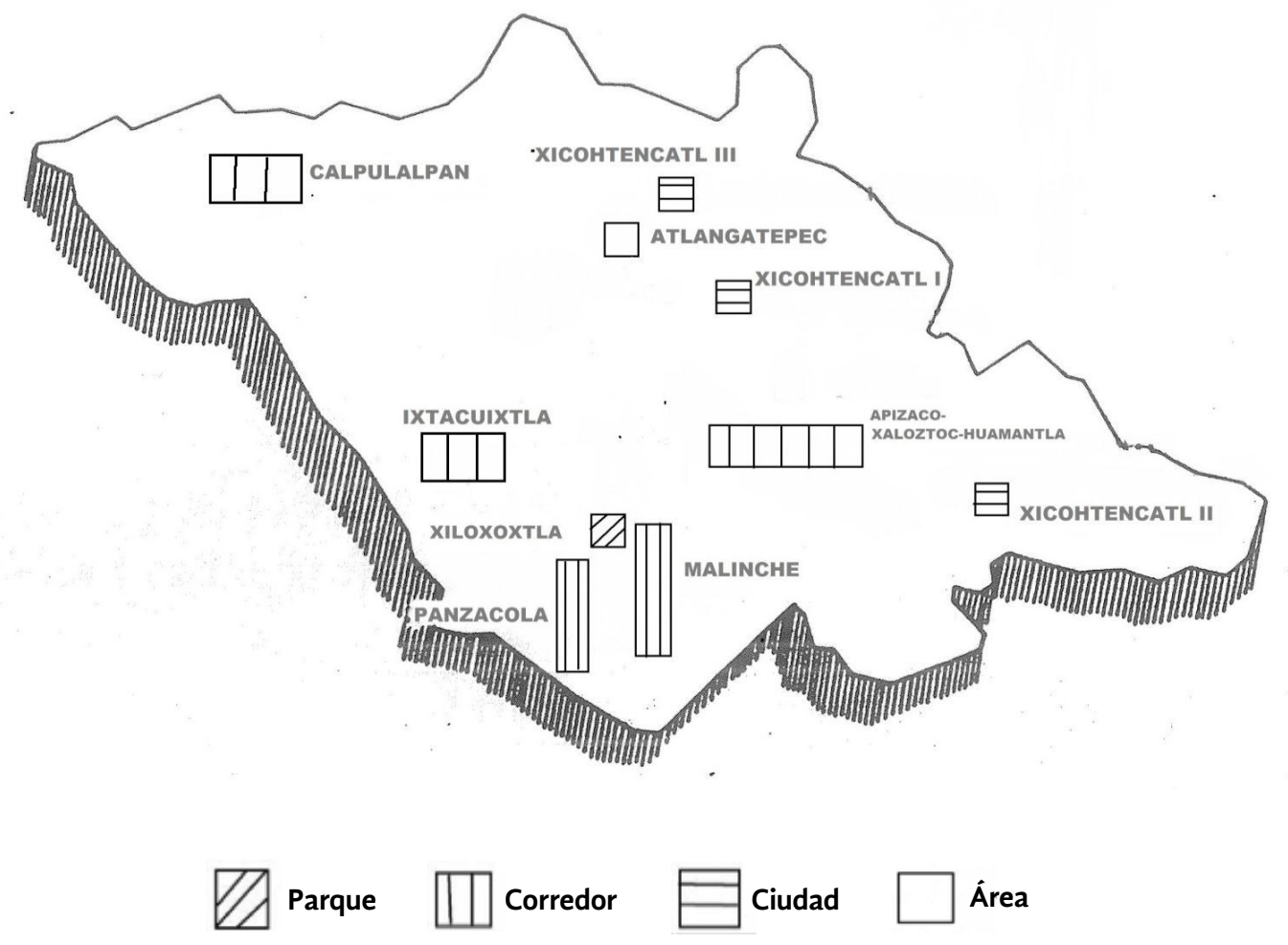

Fuente: Elaboración propia con base en Ley para el Fomento Industrial en el estado de Tlaxcala 1973.

El mapa 2 refleja en 1998 una importante expansión de la estructura industrial de Tlaxcala, producto de la modificación y el ordenamiento territorial en la materia. En 25 años, desde 1973 hasta 1998 se crearon 10 zonas industriales, sumando 3 parques, 3 corredores, 2 ciudades y 2 áreas industriales, distribución que permitió un equilibrio regional al diversificarse su oferta en el territorio local. 
Mapa 2. Tlaxcala: localización de los corredores, ciudades, parques y áreas industriales de en 1998.

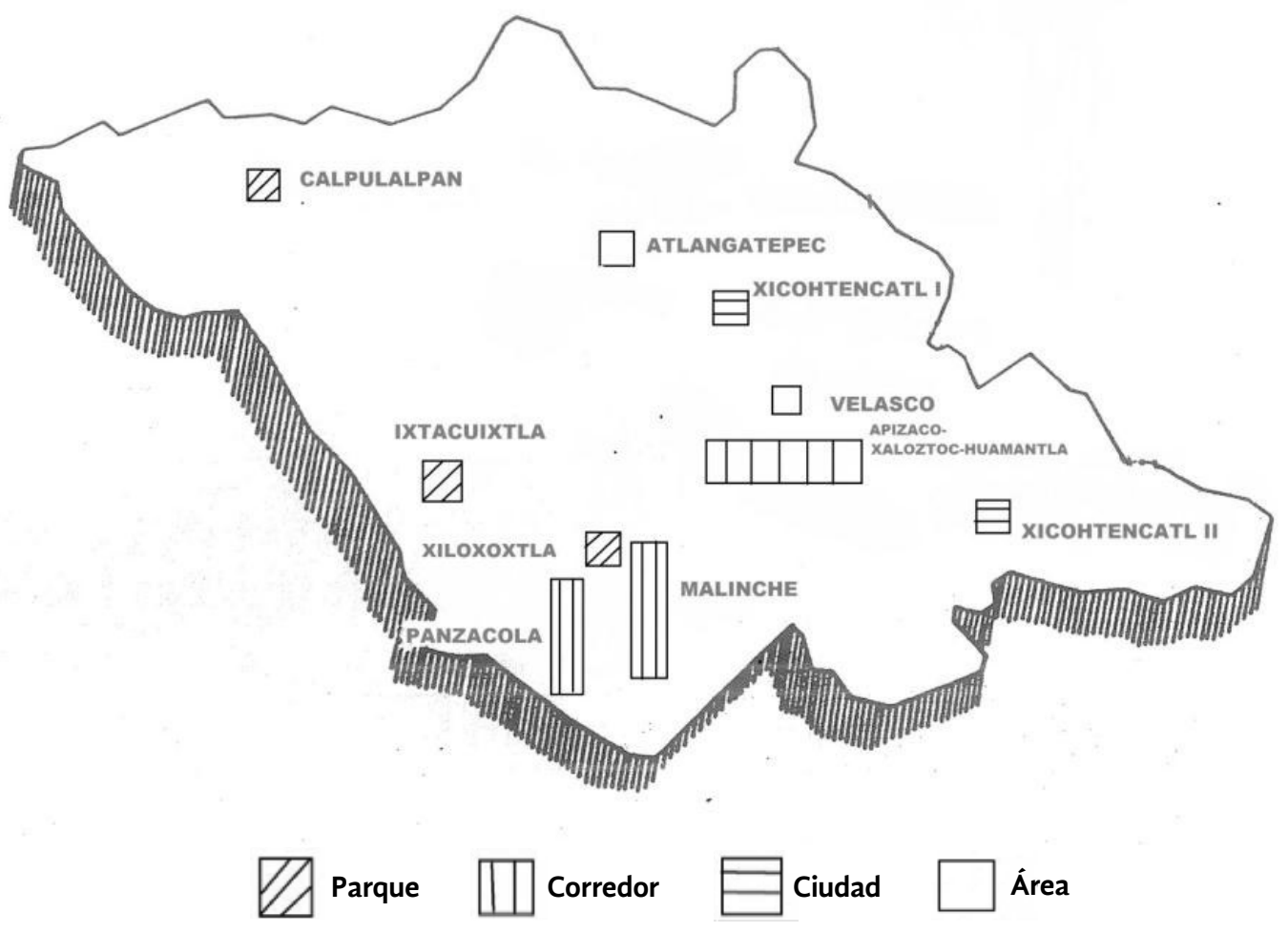

Fuente: Elaboración propia con base en la

Ley de Fomento Económico del estado de Tlaxcala 1998.

Las diferencias que se observan entre el mapa 1 y el mapa 2 además del incremento de la estructura industrial, son las modificaciones en la nominación de los corredores de 1973 y la transformación de uno de ellos. En el caso del Corredor Apizaco-Huamantla, se incorpora al municipio de Xaloztoc, quedando como Corredor Apizaco-Xaloztoc- Huamantla; en cuanto al Corredor Texmelucan-Tlaxcala, se transforma en Parque Industrial Ixtacuixtla. La expansión de la estructura industrial y sus cambios buscaron facilitar la elección del capital manufacturero para su alojamiento en las zonas industriales, determinaciones que fueron acompañadas por otros apoyos a la inversión.

Cuatro años más tarde, durante la administración de Alfonso Sánchez Anaya, primer gobernador que marcó la transición política en el estado de Tlaxcala, se publicó este instrumento jurídico, cuyo objeto fue establecer las bases a las que se apegó el desarrollo económico de la entidad; el desarrollo de la infraestructura para el crecimiento económico; la promoción de inversiones; la simplificación administrativa y la mejora regulatoria, temas marcados por las reformas estructurales para continuar abriendo la economía a la inversión extranjera; así como el desarrollo de la cultura protectora de los derechos de los trabajadores y sus condiciones socioeconómicas.

El mapa 3 refleja, en el territorio estatal, el máximo ordenamiento industrial alcanzado desde 1973, pues a la estructura industrial contemplada en la Ley de 1998 se suman otras 2 zonas industriales, ha- 
ciendo un total de 12 integrada por 5 corredores, 3 ciudades, 3 áreas y 1 parque industrial. Ya en este periodo se observa una mayor distribución de las zonas industriales en las regiones pero predominan la centro-norte y centro sur.

Mapa 3. Localización de los corredores, ciudades, parques y áreas industriales de Tlaxcala en 2002

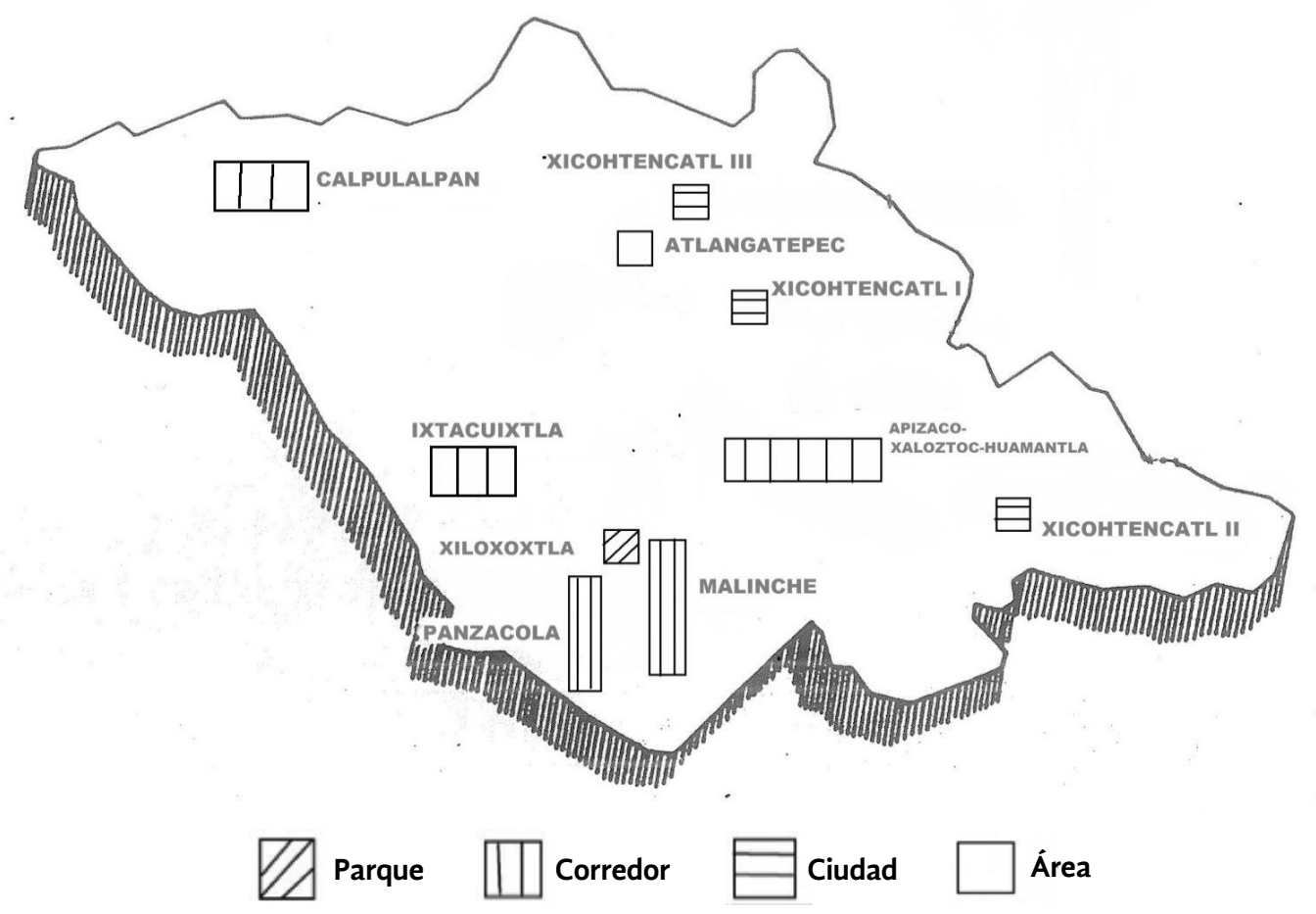

Fuente: Elaboración propia con base en la Ley de Fomento Económico del estado de Tlaxcala 2002.

Posterior a la ley de 2002, durante la administración de Héctor Ortiz Ortiz, emerge otra Ley de Fomento Económico en diciembre de 2009. Entre los propósitos de este instrumento jurídico figuran los de promover, fomentar e incentivar la actividad económica y generar un entorno favorable para su desarrollo; promover las inversiones mediante la simplificación administrativa; incentivar la generación de nuevas fuentes de empleo y consolidar las existentes, mediante la promoción y apoyo a la competitividad de las empresas [condición para la deslocalización y relocalización industrial] y fortalecer el sistema de apertura rápida de empresas; entre las principales.

Durante este periodo se observa una contracción de la estructura industrial, pues en la Ley de 2009 son eliminadas las áreas de Velasco y Tecopilco, situación que mantiene la polarización regional. Los corredores, ciudades, parques y áreas industriales reconocidos en este instrumento jurídico esquematizan el proceso ordenador y transformador realizado en el territorio desde 1973 el cual es vigente hasta la fecha.

En materia fiscal no hubo claridad en los estímulos municipales al no precisar los conceptos y porcentajes de apoyo a las empresas. Lo anterior reflejó desinterés por el sector manufacturero, pues, bajo esa administración se estimuló la llegada del capital comercial al construirse "El Gran Patio". Su ubicación 
articuló territorialmente la capacidad de oferta con la capacidad de consumo no sólo de los más de 499 mil habitantes de los 19 municipios que integran la Zona Metropolitana Apizaco-Tlaxcala, sino también del norte y oriente de la entidad y de la región norteña del estado de Puebla. La logística y conexión carretera favoreció el alcance de este proyecto partícipe del proceso de acumulación en la parte de la realización final de las mercancías.

Desde 1973 los elementos centrales de los instrumentos jurídicos: el ordenamiento territorial (creación de zonas industriales) y los incentivos fiscales (reducciones y exenciones), además de la construcción de infraestructura (equipamiento y servicios), han constituido la propuesta de los gobiernos estatales para incentivar la localización de las empresas industriales. El cuadro 1 muestra la síntesis sobre la instalación de las zonas industriales a partir de las cuatro leyes emitidas.

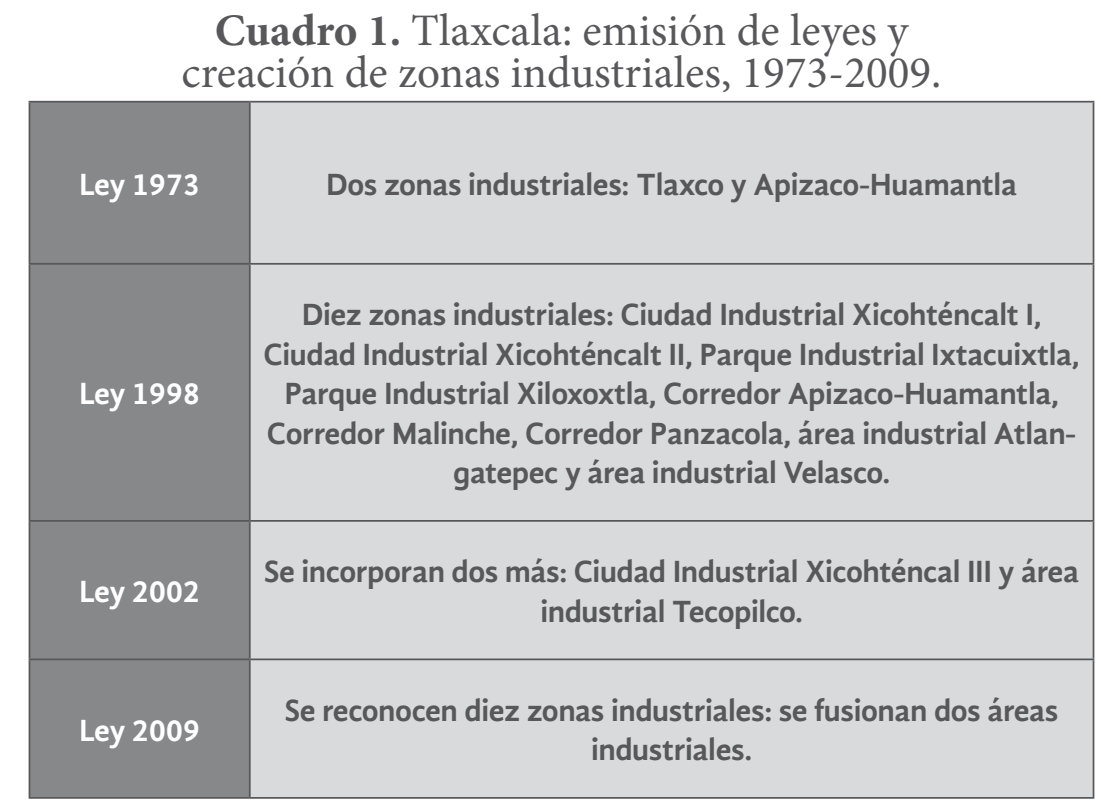

Fuente: Elaboración propia con base en las Leyes de Fomento Industrial y Económico de 1973, 1998, 2002 y 2009 para el estado de Tlaxcala.

Las alternativas de localización ofertadas no han escapado al contexto de competencia desigual entre las entidades y regiones, siendo ésta una de las consecuencias de la descentralización del ordenamiento territorial y urbano, ahora a cargo de los gobiernos locales. En esta pugna disímil las regiones ganadoras son las que ofrecen más, por ello, la creación y dispersión de las zonas industriales en la geografía estatal amplió las opciones de elección al capital y creó condiciones de competencia interna y externa.

En relación a los estímulos y apoyos fiscales que el Gobierno del Estado ha ofrecido para atraer y estimular la inversión y reinversión industrial, permiten las condiciones óptimas de reproducción y acumulación del capital, relacionadas con los factores tradicionales como la disponibilidad de mano de obra barata, la cercanía con el mercado, materias primas, infraestructura carretera que permite la conexión de todos estos elementos. El cuadro No. 2 muestra el esquema de subsidios, exenciones y reducciones fiscales que el gobierno estatal ha ofrecido desde 1973. 
- Revista de Ciencias Sociales y Humanidades. ISSN-P: 0188-9834 ISSN-E: 2395-8669.

Cuadro 2. Tlaxcala: subsidios, exenciones y reducciones fiscales, 1973-2009.

\begin{tabular}{|c|c|c|c|c|}
\hline $\begin{array}{c}\text { Subsidios, Exenciones y Reduccio- } \\
\text { nes Fiscales }\end{array}$ & $\begin{array}{l}\text { Ley } 1973 \text { Art. } \\
7,9,10\end{array}$ & $\begin{array}{l}\text { Ley } 1998 \\
\text { Art. } 20\end{array}$ & $\begin{array}{l}\text { Ley } 2002 \text { Art. } \\
22\end{array}$ & Ley 2009 Art. 31 \\
\hline $\begin{array}{l}\text { - Subsidio a industrias nuevas Im- } \\
\text { puesto Sobre Ingresos Mercantiles } \\
\text { (participación correspondiente al } \\
\text { Edo.) }\end{array}$ & $\begin{array}{l}\text {-Hasta del } 1.2 \% \\
\text { tasa general. }\end{array}$ & & & \\
\hline $\begin{array}{c}\text { - Exención de impuesto predial, } \\
\text { (industrias nuevas y ampliacio- } \\
\text { nes). }\end{array}$ & $\begin{array}{l}\text { - Hasta por } 20 \\
\text { años. }\end{array}$ & & & \\
\hline $\begin{array}{l}\text {-Escrituras de constitución de } \\
\text { sociedades, para establecer indus- } \\
\text { trias en el edo., y compra-venta de } \\
\text { terrenos de industrias nuevas. }\end{array}$ & $\begin{array}{l}\text {-No causan dere- } \\
\text { chos de registro }\end{array}$ & & & \\
\hline $\begin{array}{l}\text { - Reducción en el pago del } \\
\text { Impuesto Sobre Nóminas a las } \\
\text { empresas nuevas. (S.F.) }\end{array}$ & $50 \%-100 \%$ & $50 \%-100 \%$ & $\begin{array}{l}50 \%-100 \% \\
\text { por } 5 \text { años }\end{array}$ & \\
\hline $\begin{array}{l}\text { Reducción en el pago del im- } \\
\text { puesto predial a inmuebles de } \\
\text { empresas nuevas y ampliaciones. } \\
\text { (Ayto). }\end{array}$ & $\begin{array}{l}60 \%-100 \% \text { por } \\
5 \text { años }\end{array}$ & $\begin{array}{l}50 \%-100 \% \\
\text { por } 5 \text { años }\end{array}$ & No señala & \\
\hline $\begin{array}{l}\text { - Reducción en pago de derechos } \\
\text { por licencias de construcción a } \\
\text { empresas nuevas y ampliaciones. } \\
\text { (Ayto). }\end{array}$ & $50 \%-100 \%$ & $50 \%-100 \%$ & No señala & \\
\hline $\begin{array}{l}\text { - Reducción de inscripción de } \\
\text { escrituras sobre constitución de } \\
\text { Sociedades (nuevas empresas), y } \\
\text { títulos de propiedad de inmuebles } \\
\text { (instalación nuevas empresas y } \\
\text { ampliaciones).(R.P.P.) }\end{array}$ & $25 \%-70 \%$ & $25 \%-70 \%$ & $50 \%-100 \%$ & \\
\hline
\end{tabular}


- Revista de Ciencias Sociales y Humanidades. ISSN-P: 0188-9834 ISSN-E: 2395-8669.

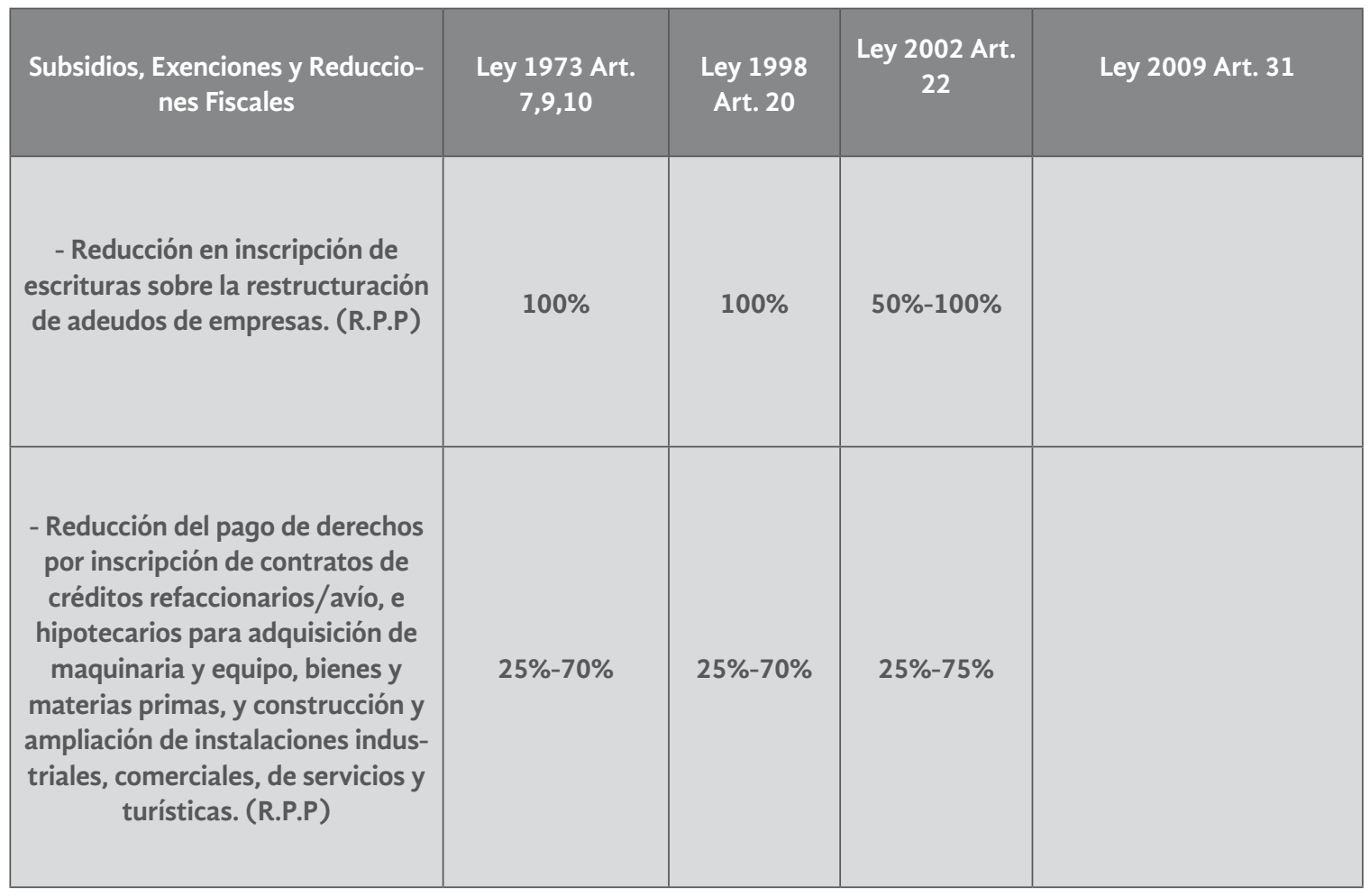

Fuente: Elaboración propia con base en las Leyes de Fomento Industrial y Económico de 1973, 1998, 2002 y 2009, publicadas en el Periódico Oficial del Gobierno del Estado.

La eficiencia funcional del capitalismo en el estado de Tlaxcala se fue edificando al amparo de los instrumentos de política nacional y estatal. A través de ellos, se determinó y promovió la localización industrial y el ordenamiento territorial mediante la creación de zonas industriales, la construcción de infraestructura y el otorgamiento de estímulos, logrando el incremento de la estructura manufacturera entre 1975 y 1999. Estos resultados se observan en el cuadro No. 3.

Cuadro 3. Tlaxcala: empresas y empleos creados y vigentes, 1975-2010.

\begin{tabular}{|c|c|c|c|c|c|}
\hline Periodo & Gobierno Estatal & $\begin{array}{c}\text { Empresas } \\
\text { Creadas }\end{array}$ & $\begin{array}{c}\text { Empresas } \\
\text { Vigentes }\end{array}$ & $\begin{array}{c}\text { Empleos } \\
\text { creados }\end{array}$ & $\begin{array}{c}\text { Empleos } \\
\text { vigentes }\end{array}$ \\
\hline $1975-1981$ & Emilio Sánchez Piedras & 34 & 17 & 6772 & 2374 \\
\hline \multicolumn{2}{|c|}{$\begin{array}{c}\text { 1981-1987 } \\
\text { Tulio Hernández Gómez }\end{array}$} & 52 & 30 & 7145 & 5425 \\
\hline $1987-1993$ & Beatriz Paredes Rangel & 62 & 40 & 5755 & 3001 \\
\hline $1993-1999$ & José Antonio Álvarez & 94 & 48 & 17209 & 7777 \\
\hline
\end{tabular}




\begin{tabular}{|c|c|c|c|c|c|}
\hline \multirow{2}{*}{ Periodo } & Gobierno Estatal & $\begin{array}{c}\text { Empresas } \\
\text { Creadas }\end{array}$ & $\begin{array}{c}\text { Empresas } \\
\text { Vigentes }\end{array}$ & $\begin{array}{c}\text { Empleos } \\
\text { creados }\end{array}$ & $\begin{array}{c}\text { Empleos } \\
\text { vigentes }\end{array}$ \\
\hline 1999-2005 & Alfonso Sánchez Anaya & n.d & 51 & n.d & 6945 \\
\hline $2005-2011$ & Héctor Ortiz Ortiz & n.d & 47 & n.d \\
\hline & Total & 242 & 233 & 36,881 & 32,006 \\
\hline
\end{tabular}

Nota: El último año de cada sexenio únicamente abarca hasta el 14 de enero, por lo que el periodo se cierra al 2010. Fuente: Elaborado con base en datos del Directorio Industrial 1999 y 2012. Secretaría de Desarrollo Industrial. Gobierno del Estado de Tlaxcala.

Resaltan las cifras de la administración de José Antonio Álvarez Lima (1993-1999), con 94 empresas instaladas aunque para el 2010 sólo se encontraban funcionando 48 y poco menos de 8 mil empleos, igualando prácticamente el número de empleos creados en conjunto por sus antecesores, y de sus predecesores. Este dinamismo laboral, durante su gobierno se sustentó al conectar el territorio estatal con la maquila global de grandes empresas como Olivetti Lexicon Mexicana (1993), Lindavista de Tlaxcala (1994) y Vista de Huamantla (1998), empresas que redituaron a la entidad poco más de 6,600 empleos. La maquila local enlazada a las grandes cadenas comerciales del mundo convirtió a Tlaxcala en un gran costurero. Este periodo se ubica en el contexto de la apertura comercial y los tratados de libre comercio calificados como los principales instrumentos de fomento industrial.

Los datos del cuadro 3 muestran la estructura manufacturera total del periodo 1975- 2010. Por ejemplo, en la administración de Emilio Sánchez Piedras se instalaron 34 empresas y se crearon 6, 772 empleos; ahora con los números actualizados se observa la subsistencia de 17 empresas de esas 34 originales, y sólo 2, 374 empleos. En este caso, después de más de 30 años, 17 empresas fueron capaces de subsistir a los procesos cíclicos de crisis y reconversión industrial, manteniendo sus operaciones productivas. Esta planta manufacturera opera de manera general, con determinadas condiciones de infraestructura como equipamiento, urbanización, servicios y comunicaciones y transportes, encontrando en todas las zonas industriales en mayor o menor medida estos requerimientos.

Si bien los estímulos y apoyos fiscales han incidido en la decisión de localización empresarial, es pertinente señalar que los determinantes fundamentales de la localización y relocalización de las empresas, para el caso de la entidad, se sustentaron en las condiciones óptimas de reproducción y acumulación del capital, relacionadas tanto con factores tradicionales como aquéllos que dictó el cambio de modelo que buscó entre otras cosas: la disponibilidad y el costo de la mano de obra, la cercanía con el mercado, materias primas, infraestructura y servicios, los intereses geoestratégicos de las empresas y el marco regulatorio existente. 


\section{Características de las empresas flexibles de la industria de autopartes en Tlaxcala}

Si bien la industria automotriz tiene una larga data, en nuestro país, con la instalación de líneas de ensamble, fue la década de los ochenta (1983) en la cual, la política industrial en México, cambió drásticamente al dirigirse del mercado doméstico hacia el mercado mundial (Carrillo1997:194) En este nuevo modelo de industrialización para la exportación los esfuerzos se encaminaron hacia la desregulación de sectores específicos, la privatización y el fomento de la inversión extranjera directa. Fue en esta década en la que se introducen dos procesos: la introducción de maquinaria y equipo automatizado y nuevas formas de organización del trabajo (Técnicas del sistema Justo a Tiempo/Control Total de la Calidad). La mayor parte de las maquiladoras y las empresas automotrices trasnacionales, terminales y de autopartes, inician el uso de estas técnicas (Carrillo, 1997:206).

Las compañías de autopartes extranjeras localizadas en México han tenido un importante papel en el mercado doméstico y en la exportación de componentes específicos, como radiadores, cables de arnés y asientos. Las plantas de autopartes de GM, por ejemplo, pasaron a formar una nueva compañía, Delphi, intensificando sus actividades de diseño, desarrollo e investigación; cambiaron además su modelo de producción de componentes independientes por el de módulos de autopartes y sistemas integrados (Carrillo, 2012:16). Estas compañías no están distribuidas en todo el país, se instalan en las inmediaciones de las empresas armadoras con la finalidad de disminuir costos de transporte, así para el caso de las armadoras instaladas en el centro del país, se desarrollaron empresas de autopartes y lo mismo sucedió para las empresas instaladas en el norte y otras entidades federativas. Así de acuerdo con Correa(2000) Chrysler creó en 1981 su fábrica de motores en Ramos Arizpe en Coahuila; Ford construyó una fábrica de motores en Chihuahua en 1982 y una fábrica de estampado en Hermosillo Sonora, con tecnología moderna que la ubica entre las más competitivas de la compañía Ford a nivel mundial. General Motors instaló dos plantas en el complejo industrial de Ramos Arizpe, Coahuila, una para la fabricación de motores (1982) y otra para ensamblado de automóviles (1981). Nissan por su parte, construyó un complejo industrial en Aguascalientes dedicado a la fabricación de motores, estampado y fundición de aluminio (Correa, 2000:208).

En Tlaxcala, el subsector más distintivo del sistema flexible es el de autopartes (fabricación de equipo de transporte). La información actualizada indica la instalación de empresas desde 1981 en el territorio estatal, fecha que coincide con la reestructuración de la empresas, con nuevas tecnología y el uso de procesos de Justo a Tiempo y Control Total de Calidad. De acuerdo con los datos del Anuario estadístico 2014 se reportaron 16 empresas con 6571 personas ocupadas, donde 6 de ellas eran pequeñas, 4 medianas y 5 grandes. Su importancia radica en ser el segundo mayor generador de empleo después de la fabricación de prendas de vestir, está última cuenta con 34 empresas y ofrece empleo a 6845 personas (Anuario Estadístico, 2014: Cuadro 17.2).

Para conocer datos específicos y la ubicación de las empresas del subsector, se obtuvo información de los Directorios Industriales de la Secretaría de Turismo y Desarrollo Económico del Gobierno del Estado de Tlaxcala, pues es la única institución que tiene registro oficial de las empresas manufactureras en la entidad. Así al consultar estos documentos encontramos 18 empresas.

El cuadro No.4 ordena datos recientes de las empresas flexibles del subsector. Cabe señalar que la información de 9 empresas, se obtuvieron directamente de las entrevistas realizadas y de las restantes 9 
Revista de Ciencias Sociales y Humanidades. ISSN-P: 0188-9834 ISSN-E: 2395-8669.

compañías fue tomada de los Directorios Industriales, mediante un ejercicio de combinación sobre localización, año de instalación, número de trabajadores, tamaño de la empresa, origen del capital, destino de la producción y tipo de productos.

\begin{tabular}{|c|c|c|c|c|c|}
\hline Empresa & Año & Trabajadores & $\begin{array}{l}\text { Origen } \\
\text { Capital }\end{array}$ & $\begin{array}{l}\text { Destino } \\
\text { Producción }\end{array}$ & Productos \\
\hline $\begin{array}{c}\text { 1.Arcomex S.A. } \\
\text { de C.V }\end{array}$ & 1995 & 575 & Nacional & Exportación & $\begin{array}{l}\text { Manufactura de } \\
\text { arnés eléctrico }\end{array}$ \\
\hline $\begin{array}{l}\text { 2.Carrocerías } \\
\text { Corpus Christi, } \\
\text { S.A. de C.V. }{ }^{*}\end{array}$ & 2004 & 56 & Nacional & Nacional & $\begin{array}{c}\text { lataformas, Cajas } \\
\text { secas, Low-boy, } \\
\text { tolvas, Volteos, } \\
\text { semirremolques }\end{array}$ \\
\hline $\begin{array}{l}\text { 3. Eissmann Au- } \\
\text { tomotive Group, } \\
\text { S.A. de C.V. * }\end{array}$ & 2012 & 500 & Alemania & Nacional/EE.UU & $\begin{array}{l}\text { alancas de velo- } \\
\text { cidad automáti- } \\
\text { cas, tableros de } \\
\text { instrumentos e } \\
\text { interiores. }\end{array}$ \\
\hline $\begin{array}{c}\text { 4. Empaques } \\
\text { y Suministros } \\
\text { Industriales S.A. } \\
\text { de C.V.* }\end{array}$ & 1985 & 31 & N.D. & Nacional & $\begin{array}{l}\text { Shampoo para } \\
\text { manos, des- } \\
\text { engrasantes y } \\
\text { desinfectantes. }\end{array}$ \\
\hline $\begin{array}{l}\text { 5. Euwe Eugen } \\
\text { Wexler de Méxi- } \\
\text { co, S.A. de C.V* }\end{array}$ & 1993 & 398 & Alemania & $\begin{array}{c}\text { Nacional/expor- } \\
\text { tación }\end{array}$ & $\begin{array}{l}\text { Consolas y } \\
\text { recubrimientos } \\
\text { automotrices. }\end{array}$ \\
\hline $\begin{array}{l}\text { 6. Global Flock } \\
\text { de México S. De } \\
\text { R. L. de C.V. * }\end{array}$ & 2009 & 60 & Nacional & $\begin{array}{c}\text { Nacional/expor- } \\
\text { tación }\end{array}$ & $\begin{array}{l}\text { Recubrimiento } \\
\text { de guanteras, } \\
\text { pilares y des- } \\
\text { cansabrazos. }\end{array}$ \\
\hline $\begin{array}{c}\text { 7. Grammer } \\
\text { Automotive de } \\
\text { Puebla, S.A. de } \\
\text { C.V. }\end{array}$ & 1999 & 421 & Alemania & $\begin{array}{c}\text { Nacional/expor- } \\
\text { tación }\end{array}$ & $\begin{array}{c}\text { Cabeceras y } \\
\text { coderas para } \\
\text { asientos de au- } \\
\text { tos. Fabricación } \\
\text { de engranes de } \\
\text { ejes y crucetas. }\end{array}$ \\
\hline $\begin{array}{l}\text { 8. Grupo Dana } \\
\text { México, For- } \\
\text { jas Tlaxcala, S.A. } \\
\text { de C.V. * }\end{array}$ & 2006 & 49 & EE.UU & EE.UU & $\begin{array}{c}\text { Frenos de mano } \\
\text { y palancas de } \\
\text { velocidades. }\end{array}$ \\
\hline $\begin{array}{l}\text { 9. Haas Automo- } \\
\text { tive de México, } \\
\text { S.A. de C.V. }\end{array}$ & 1998 & 105 & Alemania & $\begin{array}{c}\text { Nacional/expor- } \\
\text { tación }\end{array}$ & $\begin{array}{c}\text { Fabricación de } \\
\text { interiores de } \\
\text { plástico. }\end{array}$ \\
\hline $\begin{array}{l}\text { 10. Interiores } \\
\text { Automotrices, } \\
\text { S.A. de C.V. }{ }^{*}\end{array}$ & 2011 & 160 & Alemania/Nac. & $\begin{array}{c}\text { Nacional/expor- } \\
\text { tación }\end{array}$ & $\begin{array}{c}\text { Estampado para } \\
\text { carrocería. }\end{array}$ \\
\hline
\end{tabular}


- Revista de Ciencias Sociales y Humanidades. ISSN-P: 0188-9834 ISSN-E: 2395-8669.

\begin{tabular}{|c|c|c|c|c|c|}
\hline Empresa & Año & Trabajadores & $\begin{array}{l}\text { Origen } \\
\text { Capital }\end{array}$ & $\begin{array}{l}\text { Destino } \\
\text { Producción }\end{array}$ & Productos \\
\hline $\begin{array}{l}\text { 11. Intemec S.A. } \\
\text { de C.V. * }\end{array}$ & 2010 & 130 & Nacional & $\begin{array}{c}\text { Nacional/expor- } \\
\text { tación }\end{array}$ & $\begin{array}{l}\text { Inyección de } \\
\text { plástico, floqueo } \\
\text { y pintado de pie- } \\
\text { zas de plástico }\end{array}$ \\
\hline $\begin{array}{c}\text { 12. Inyección } \\
\text { y espumado } \\
\text { automotriz de } \\
\text { México, S.A. de } \\
\text { C.V }\end{array}$ & 2008 & 30 & N.D. & N.D. & $\begin{array}{l}\text { Asientos metá- } \\
\text { licos (inyección } \\
\text { poliuretano). }\end{array}$ \\
\hline $\begin{array}{c}\text { 13. Johnson Con- } \\
\text { trols Automotive } \\
\text { México, S.A. de } \\
\text { C.V. * }\end{array}$ & 1981 & 700 & EE.UU & $\begin{array}{c}\text { Nacional/expor- } \\
\text { tación }\end{array}$ & $\begin{array}{l}\text { Fabricación y } \\
\text { ensamble de } \\
\text { asientos para } \\
\text { automóviles. }\end{array}$ \\
\hline $\begin{array}{l}\text { 14. Lear Corpo- } \\
\text { ration México, S. } \\
\text { de R.L. de }\end{array}$ & 2012 & 600 & EE.UU & $\begin{array}{c}\text { Nacional/expor- } \\
\text { tación }\end{array}$ & $\begin{array}{l}\text { Protección para } \\
\text { arneses, siste- } \\
\text { mas mecatróni- } \\
\text { cos y electróni- } \\
\text { cos. Fabricación } \\
\text { de manguera y } \\
\text { componentes } \\
\text { eléctricos }\end{array}$ \\
\hline $\begin{array}{l}\text { 15. Schlemmer, } \\
\text { S.A. de C.V. }\end{array}$ & 2011 & 100 & Alemania & $\begin{array}{c}\text { Nacional/expor- } \\
\text { tación }\end{array}$ & $\begin{array}{l}\text { Diseño, desarro- } \\
\text { llo y fabricación } \\
\text { de arneses } \\
\text { eléctricos. }\end{array}$ \\
\hline $\begin{array}{l}\text { 16. SE Bordnetze } \\
\text { - México S.A. de } \\
\text { C.V. }{ }^{*}\end{array}$ & 2007 & 2165 & Japón/Alemania & Exportación & $\begin{array}{c}\text { Piezas troquela- } \\
\text { das, maquinadas } \\
\text { y ensambles } \\
\text { de soldadura } \\
\text { para la industria } \\
\text { automotriz. }\end{array}$ \\
\hline $\begin{array}{c}\text { 17. Somatics de } \\
\text { México S.A de } \\
\text { C.V. }\end{array}$ & 2000 & 57 & N.D. & Nacional & $\begin{array}{c}\text { Inyección de } \\
\text { piezas plásticas }\end{array}$ \\
\hline $\begin{array}{l}\text { 18. Treck Plas- } \\
\text { tick, S. De R.L. } \\
\text { de MI }\end{array}$ & 2009 & 100 & N.D. & & \\
\hline
\end{tabular}

Fuente: Elaborado con base en diversos Directorios de la Secretaría de Desarrollo Económico (SEDECO) hoy Secretaría de Turismo y Desarrollo Económico (SETYDE) del Gobierno del Estado y entrevistas con empresarios 2014.

Directorio Empresarial Tlaxcala. Octubre, 2010. SEDECO.

Directorio Industrial del estado de Tlaxcala. Edición 2011.

SEDECO. Directorio Industrial del estado de Tlaxcala. Edición 2012. SEDECO.

Directorio Sector Automotriz. 2014. SETYDE.

* Empresas entrevistadas 
De lo anterior se desprenden las siguientes características:

\section{Localización}

Las 18 empresas de equipo de transporte están localizadas en 11 municipios del territorio, sobresaliendo Papalotla (4), Tetla (3) y Tlaxco (3). Las regiones sur y centro norte concentran el $44.4 \%$ y $38.8 \%$ de empresas, respectivamente.

Del total de empresas, 14 están emplazadas en zonas industriales (77.8\%) y 4 operan en zonas urbanas $(22.2 \%)$.

\section{Año de instalación.}

Los datos apuntan el inicio de operaciones de 2 empresas en la década de los años ochenta del siglo anterior, 4 más lo hicieron en la década de los noventa y la mayoría, 12 empresas que equivalen al 66.6\% se instalaron a partir del año 2000.

Tamaño de las empresas y empleo

Se observa la preminencia de empresas medianas (9) y grandes (7), que representan el $50.0 \%$ y $38.9 \%$, respectivamente. Las pequeñas suman apenas 2 unidades productivas.

Los datos obtenidos indican actualmente la operación de 18 empresas, una más de las reportadas en el Anuario Estadístico y Geográfico de Tlaxcala 2013, y ocupan a 6,237 personas.

\section{Origen del capital y destino de la producción}

Por el origen del capital, 4 empresas son de participación nacional (22.2\%); 9 de participación extranjera (50.0\%) (5 de Alemania y 3 de Estados Unidos, 1 coinversión Alemania/Japón); 1 es combinada con capital nacional y extranjero (Alemania) y no existe información de 4 empresas.

Tres empresas orientan su producción al mercado nacional; 3 exportan; 5 combinan su producción al mercado interno y externo; 5 exportan indirectamente al destinar su producción a empresas exportadoras y no existe información de 2 empresas.

Elementos de localización de las empresas.

Se distinguieron tres:

Cercanía con el mercado

Logística carretera: conectividad y movilidad

Costo de mano y características de mano de obra

La cercanía relativa al mercado, los avances en comunicaciones y transportes acortan distancias, lo anterior ha permitido que más de la mitad de las empresas se encuentren localizadas en la región centronorte y centro sur de la entidad. El factor primordial de la localización es la cercanía al mercado (cliente) las empresas no abandonan el entorno inmediato de la armadora (VW). Estos elementos fueron los 
"atractores" que consideraron las empresas para instalarse en la entidad. Sin embargo, al parecer, son las empresas de menor importancia. En estas se utilizan mano de obra barata, sin tradición sindical y de baja calificación (González,2008: 34).

Lo anterior indicaría el predominio de factores weberianos ${ }^{7}$ en la localización de las empresas en la entidad? Y las zonas industriales de los años setenta como el lugar de su alojamiento?

\section{Consideraciones finales}

La crisis de sobreacumulación en la década de los años setenta del siglo XX, obligó al capitalismo a restructurar sus propias contradicciones dando origen al posfordismo o forma flexible de producción. Esa gradual transformación productiva fue acompañada por reformas neoliberales derivadas del Consenso de Washington que colocaron al mercado en el centro de las decisiones económicas, desplazando al Estado como el ente impulsor y conductor del desarrollo, sobre todo en los países atrasados.

Con la restructuración y las reformas neoliberales, las grandes empresas transnacionales de los países capitalistas consolidaron su dominio global, a costa del subdesarrollo de los países atrasados, y desplazaron sin obstáculos su fragmentación productiva hacia territorios con fuerza de trabajo barata para retomar la competitividad perdida durante la crisis del fordismo.

El propósito de la investigación consistió en observar las características flexibles de una de las industrias más representativas de esa forma productiva, como son las empresas de autopartes ubicadas en el estado de Tlaxcala e identificar los elementos que permitieron su localización en la entidad.

Cabe señalar dos hallazgos que desde nuestra perspectiva otorgan particularidad al trabajo realizado: $1^{\circ}$. Teóricamente Ramírez y Hauser (1996) al ponderar el predominio de los factores weberianos en las viejas zonas industriales -espacios identificados para la localización de empresas fordistas- prácticamente las descartan como espacios propicios para las empresas usuarias del sistema flexible, dados los diferentes factores de localización de éstas, distintos a los weberianos; aunque reconocen la existencia de antiguas zonas industriales como importantes receptoras de plantas con procesos de Justo a Tiempo.

Sobre la misma idea Bellisario (2001), afirma la declinación de las viejas áreas industriales del mundo, señalamiento que no es absoluto, pues las condiciones de la estructura industrial en los países desarrollados son incomparables a las de los países en desarrollo. En los primeros, dicha aseveración tiene cabida por las características en que se desenvuelve la flexibilidad del sector manufacturero y donde las viejas zonas industriales ya no son referentes de localización; mientras que en los segundos, como en nuestro caso, las viejas zonas industriales, en algunos casos, se han adaptado a las diferentes condiciones exigidas por la globalización productiva, y siguen siendo espacios de alojamiento industrial, como es el caso del estado de Tlaxcala.

Estos planteamientos, desde luego no desacreditan a las tradicionales zonas industriales, pues su antigüedad y declinación sólo son referidos en términos del contexto global actual que establece relaciones

7- Weber, encamino sus planteamientos retomando las aportaciones de la escuela neoclásica. Para ello asume, entre otras cosas, los rendimientos constantes a escala; disponibilidad de insumos para la producción en forma ilimitada; de igual forma indicó que los insumos están localizados en pocas fuentes. Por el lado de la demanda, esta se mantiene fija y en cada lugar, y los costos de transporte, para cada bien, son directamente proporcionales a su peso y a la distancia que transportan. De igual considera las ventajas que da la aglomeración de empresas. 
productivas en condiciones diferentes de interacción, colaboración y complementariedad. La información obtenida de los directorios industriales y del instrumento aplicado, confirmaron efectivamente, que la mayoría de las empresas flexibles de autopartes, realizan sus funciones productivas dentro de las zonas industriales de la entidad. Sin embargo, en estas zonas industriales, entre empresas, no existe relación productiva, es el caso de las ciudades y corredores industriales de Tlaxcala existen plantas de diversa subdivisión, rama, giro, tamaño y orientación, aparentemente sin ninguna interacción. Sin embargo, esto no descarta, que estas empresas sean parte de un eslabón de la misma industria automotriz y que por lo tanto se instalen en la entidad, con relativa cercanía a las empresas ensambladoras del centro del país, en particular de Volkswagen. Así se explicaría porque más del 77\% del total de las unidades productivas funcionan en los corredores industriales de la entidad.

De esta manera, desde las relativamente viejas zonas industriales de Tlaxcala las empresas flexibles de autopartes se articulan a la cadena global de producción, pues el origen de su capital, el destino de su producción, el lugar de sus principales proveedores y el suministro de tecnología se localizan en el exterior. Sin embargo, la entidad cuenta con la infraestructura carretera que permite desplazarse rápidamente, al puerto de Veracruz, Tampico (lugares de embarque para las exportaciones) así como su rápida vinculación con el centro, sur y norte del país.

$2^{\circ}$. Las exposiciones teóricas de Ramírez y Hauser (1996) sobre el emplazamiento a corta distancia de los proveedores para la aplicación del Justo a Tiempo, es decir, la cercanía radial de los proveedores de empresas flexibles [como la automotriz], en este caso de la empresa Volkswagen, en el caso de las empresas flexibles de autopartes en Tlaxcala, el resultado fue que los proveedores no están en su cercanía más inmediata. Sin embargo, el tiempo de traslado a las empresas automotrices del centro del país es muy corto.

Por otro lado, dentro de la investigación reviste alta importancia insistir en dos aspectos relacionados con la composición orgánica del capital. El incremento de la tecnología dentro de las manufacturas y la baja absorción de la fuerza de trabajo, observada desde el periodo de industrialización por sustitución de importaciones se profundizan en el modelo post-fordista. Un ejemplo ilustrativo es la industria de autopartes de Tlaxcala, donde las ganancias superan en 2.3 veces el monto de las remuneraciones. Esto ayuda a explicar porque a pesar del bajo crecimiento de la economía mexicana se registran altas ganancias en sectores estrechamente vinculados a la cadena global de valor, como la industria automotriz y sus proveedores de autopartes, quienes sustentan su competitividad y elevados dividendos gracias a las bajas remuneraciones de la fuerza de trabajo; los reducidos salarios -agravados por la subcontrataciónexplican porque ésta, cada vez tiene menor peso en la composición orgánica del capital. Pero además, el capital recurre a la menor durabilidad de las mercancías como el medio para acelerar su rotación y seguir incrementando sus ganancias. Esa característica pone el dedo en la llaga ante un vergonzante episodio del voraz desarrollo capitalista.

En estudios de otras entidades, como Sonora (Galicia y Sánchez, 2011: 189-190) reportaron el bajo encadenamiento que tienen los productores locales con, la empresa automotriz armadora ubicada en Hermosillo, en este caso la empresa transnacional Ford, la cual lleva buen tiempo funcionando en esta entidad federativa. Las causas que estos investigadores sugieren, de la falta de articulación tienen que ver, entre otras cosas: con la ausencia de una cultura empresarial local, es decir ausencia de empresarios, que asuma mayores riesgos, invirtiendo en este tipo de empresas; la inadecuada política industrial aplicada 
tanto por organismos gubernamentales federales y como por las políticas estatales, entre otras cosas.

En el caso de Tlaxcala, la entidad no fue uno de los lugares elegido, por la política inicial de industrialización en los años cuarenta, por el gobierno federal sino fue hasta la década de los setenta, a partir de una política de descentralización. Con lo anterior, estamos sugiriendo que los procesos industriales en la entidad no se decidieron aquí, sino a partir de las negociaciones del gobierno federal directamente con las empresas trasnacionales y algunos empresarios nacionales. Es decir hay un componente político que no se logra ver. Estas negociaciones están asociadas con la gran cantidad de subsidios e infraestructura que se otorgan a las empresas para que se instalen.

Con la reciente reforma laboral, México ha terminado por especializase ya no en mano de obra barata, sino precaria. A pesar de ello, la promoción industrial de la entidad, a través de sus distintas gubernaturas, no ha sido suficiente, para responder a la demanda de empleo, pues el déficit en esta materia es muy elevado.

La llegada de la empresa alemana Audi, cercana al territorio estatal ha dado oportunidad al discurso oficial para considerar el crecimiento de la industria de autopartes. Sin embargo, habrá que ser cautos con la expectativa, pues las empresas proveedoras de autopartes se encuentran articuladas a la armadora y provendrán del extranjero, generalmente del país de origen de la gran industria automotriz, sobre todo porque las autopartes de estos automóviles exigen niveles de calidad que las empresas de autopartes instaladas en la entidad, probablemente no puedan cubrir, a menos que trabajen, desde el inicio de las actividades de la empresa alemana, con las especificaciones que Audi, establezca antes de echar andar la producción de sus autos. Si acaso, empresas mexicanas de menor nivel (proveedoras de estratos inferiores en el encadenamiento) podrán lograr una tenue oportunidad de enlazarse a esta trama productiva. La coyuntura entonces, será aprovechar la insuficiencia de empresas en el tercer estrato del encadenamiento: las partes para chasis, motor y transmisión; para ello deben demostrar capacidad de adaptación a los cambios en el producto y sujetarse a evaluaciones sistemáticas sobre calidad, entrega a tiempo y costos de cuyos resultados dependerá su permanencia como proveedora. A estas exigencias, son a las que probablemente los empresarios locales no quieran sujetarse.

Por otro lado y de acuerdo con lo visto en esta investigación, la llegada de más empresas de autopartes no redundará en el pago de altos salarios del personal operativo, por lo menos no a los operarios, pues lo que buscan estas empresas son precisamente salarios competitivos, es decir fuerza de trabajo barata utilizando además, el recurso del outsourcing laboral. La posibilidad de incorporar fuerza de trabajo especializada puede abrirse para los técnicos e ingenieros mexicanos que demuestren competencias para sacar proyectos de largo plazo. El costo mayor de este tipo de mano de obra, en los países de origen, puede abrir espacios para "algunos" profesionistas mexicanos en este tipo de empresas (Carrillo, 1997:222). La fuerza de trabajo si bien va perdiendo importancia en la composición orgánica del capital, sigue siendo el factor fundamental para las empresas con procesos de manufactura.

\section{Referencias}

Bialakowsky, Albert et al. 2009. La distopía en los laberintos discursivos del capital y la nueva morfología del trabajo. En Trabajo y capitalismo entre siglos en Latinoamérica, El trabajo entre la perennidad y la superfluidad (Tomo II), compilado por Alberto L, Raquel Partida, Ricardo Antunes et al. Guadalajara: 
Universidad de Guadalajara, 19-58.

Becattini, Giacomo. 1989. Los distritos industriales y el reciente desarrollo italiano. Sociología del Trabajo, 5:3-18.

Bellisario, Antonio. 2001. Territorio y economía: La teoría de la especialización flexible. II. Geografía Norte Grande, 28:43-56.

Bustos, María Luisa.1993. Las teorías de localización industrial: Una breve aproximación. Estudios regionales, 35: 51-76.

Carrillo, Jorge. 2012. La industria de autopartes en el Norte de México y el uso del Internet, El Colegio de la Frontera Norte, 47p. http://www.colef.mx/jorgecarrillo/wp-content/uploads/2012/04/PU216.pdf (14 de junio de 2016).

Carrillo, Jorge.1997. Maquiladoras automotrices en México: clusters y competencias de alto nivel. En Competitividad, redes productivas y competencias laborales. Coordinado por Martha Novick y María A.Gallart. Montevideo: OIT/CINTERFORD, 193-234.

Christaller, Walter. 1966. Central Places in Southern Germany. Prentice Hall, Englewood Cliffs, New Jersey.

Contreras, Oscar. 2000. Empresas globales, actores locales: producción flexible y aprendizaje industrial en las maquiladoras. Ciudad de México: El Colegio de México.

Correa, Antonia.2000. Red de producción de la industria automotriz en Ciudad Juárez. Ciudad de México: Universidad Autónoma Metropolitana - Unidad Xochimilco.

De la Garza, Enrique. 2012. La manufactura y la maquila en crisis y en la crisis. En Nueva estrategia de industrialización. Análisis estratégico para el desarrollo. Coordinado por José Luís Calva, Volumen 7. Ciudad de México: Universidad Nacional Autónoma de México, 240-276.

Duch, Nestor. 2005. La teoría de la localización. Universidad de Barcelona. www.eco.ub.es/ nduch/postgrau_archivos/Duch_localizacion.pdf (04 noviembre 2015).

Galicia, Fabiola y Sánchez, Isaac. 2011. La industria automotriz y el fomento a las cadenas productivas en Sonora: el caso de la Ford en Hermosillo. Economía, Sociedad y Territorio, 11 (35): 161-195.

Garza, Gustavo.1990. Impacto regional de los parques y ciudades industriales en México. Estudios Demográficos y Urbanos, 5 (3): 655-675.

Garrido, Ricardo y Gallo, María Teresa. 2006. Localización y movilidad de las empresas en España, Sevilla, Fundación EOI.

www.eoi.es/api.eoi.es/api_v1_dev.php/fedora/asset/eoi.../componente20031.pdf

(10 de octubre de 2015)

Harvey, David. 1998. La condición de la posmodernidad. Investigación sobre los orígenes del cambio cultural. Buenos Aires. Amorrortu.

Isard, Walter. 1970. Métodos de análisis regional. Barcelona, Editorial Ariel.

Kuri, Armando.2003. Aspectos teóricos del desarrollo regional. Economía informa, 321: 54-63.

Lipietz, Alain. 1994. El posfordismo y sus espacios, Las relaciones capital-trabajo en el mundo. Serie Seminarios Intensivos de Investigación, documento de trabajo No. 4: 3-18.

Martinelli, José María. 2010 Crisis capitalista: Tesis teórico-éticas. En Crisis Capitalista Mundial y Políticas Públicas, compilado por José María Martinelli. Ciudad de México: Universidad Autónoma Metropolitana, pp. 23-26. 
- Revista de Ciencias Sociales y Humanidades. ISSN-P: 0188-9834 ISSN-E: 2395-8669.

Piore, Michael y Sabel, Charles. 1990. La segunda ruptura industrial. Madrid, Alianza Editorial. Precedo, Ledo y Villarino, Monserrat.1992. La localización industrial. Madrid: Síntesis Editorial. Ramírez, José Carlos y Hauser Alí.1996. La localización industrial en los sistemas rígidos y flexibles de producción: un punto de partida para nuevos desarrollos teóricos. Economía Mexicana, 5 (1): 99-129. Salguero, Jorge. 2006. Enfoques sobre algunas teorías referentes al desarrollo regional. Sociedad Geográfica de Colombia. Bogotá.

www.economia.unam.mx/academia/inae/inae5/515.pdf

Sinisterra, Mónica María. 2009. Multilocalización: una estrategia para competir globalmente. Estudios Gerenciales, 25 (110): 85-110.

Weber, Alfred. 1929. Theory of the location of industries. Chicago: Chicago Press.

Thünen, Von. 1966. Isolated State. London: Pergamon Press. 